\title{
"dizen algunos oydores a las partes que en acuerdo les mato y me ponen mal con los litigantes": El fiscal Jerónimo de Rabanal y su participación en la Audiencia de Charcas (1561-1576)
}

\author{
“dizen algunos oydores a las partes que en acuerdo \\ les mato y me ponen mal con los litigantes": \\ The public prosecutor Jerónimo de Rabanal and his participation \\ in the Audiencia de Charcas (1561-1576) \\ Sergio H. Angeli \\ PROHAL, Instituto Ravignani, \\ Instituto de Historia del Derecho \\ Universidad de Buenos Aires-CONICET-Argentina
}

\section{Resumen}

En este trabajo, intentaremos reconstruir la actuación del fiscal de la Audiencia de Charcas, Jerónimo de Rabanal, entre los años 1561 y 1576. Nos posicionaremos en comprender primeramente cómo se construyó el oficio fiscal en Castilla para luego observar su traslado a Indias. Localmente situado en la sede del tribunal charqueño, el fiscal Rabanal enfrentó los desafíos de poseer un oficio regio de reciente implementación en las Chancillerías americanas, lo que llevó a estar gran parte del tiempo en conflictos con los oidores y el presidente letrado del tribunal. Desvelar cómo se implementó el oficio fiscal en la primera Audiencia de Charcas esperemos que arroje luz en la comprensión de una cultura jurídica localizada en los primeros tiempos de la territorialización del espacio charqueño de la monarquía católica de los Austrias.

Palabras clave: Fiscal, Audiencia de Charcas, cultura jurídica, localización

\begin{abstract}
In this paper, we will try to develop the action of the public prosecutor of the Audiencia de Charcas, Jerónimo de Rabanal, between the years 1561 and 1576. Firstly, we will try to understand how the fiscal office was created in Castilla and then analyze its transfer to the Indies. Located in the headquarters of Charcas' court, the prosecutor Rabanal faced the challenges of having a recently established office in the American Chancery, which often led to conflict with the hearers and the legal president of the court. To reveal how the fiscal office was implemented in the first Charcas Hearing hopefully will shed light on the understanding of a legal culture located in the early days of the territorialization of Charcas' area of the Austrian Catholic monarchy.
\end{abstract}

Keywords: Prosecutor, Audiencia de Charcas, legal culture, location 


\section{Introducción}

El estudio de los magistrados que cumplieron funciones en los extensos territorios de los dominios castellanos de ultramar es una herramienta esencial para comprender la lógica individual, pero también colectiva, del accionar de las diferentes Audiencias indianas. Instituciones de la real justicia, los tribunales audienciales se convirtieron en importantes centros de poder, tanto formal como simbólico, y sus ministros supieron ejercer un enorme capital político en las sedes de dichos palacios de justicia.

Las Audiencias fueron conformadas por un elenco estable de oidores, fiscales, secretarios, relatores, procuradores, abogados y porteros, entre otros oficiales reales. La vida diaria de los tribunales acontecía en un abigarrado accionar de relaciones personales, tanto hacia el interior como el exterior de ellos. Las nutridas redes clientelares, que anudaban las relaciones que los letrados supieron establecer con las principales figuras de las jurisdicciones donde impartían justicia, pone de manifiesto la necesidad de desentrañar aquellos vínculos que influyeron en las decisiones que tomaron los ministros al momento de dictar sentencia.

Por su prioritario rol, los oidores fueron estudiados con bastante detalle por diversas corrientes historiográficas, que se ocuparon tanto de su vida pública como privada en las distintas sedes de Audiencias. Sin embargo, pese a cumplir un rol central en la defensa de los intereses reales, los fiscales indianos no supieron concitar el mismo interés por parte de los investigadores contemporáneos en el análisis de sus funciones y relaciones profesionales.

Este trabajo, es una primera aproximación, al estudio del licenciado Jerónimo de Rabanal, primer fiscal de la Audiencia de Charcas entre los años 1561 y 1576. Inserto en un espacio geográfico de relevancia para la corona de Castilla, el fiscal Rabanal tuvo una ardua tarea que cumplir en la defensa de intereses más que estratégicos para la monarquía de Felipe II. Centrado en la vigilancia y control de las remesas de plata que se producían en el centro minero de Potosí, como en la protección y salvaguarda de las comunidades indígenas que aportaban la mita anual al cerro Rico, el oficio fiscal que desempeñaba Rabanal no fue menor. Sin duda, quedó inmerso en medio de intrincados intereses que no debieron ser fáciles de sortear, los que aquí intentamos analizar.

La investigación se nutrió de fuentes inéditas como éditas. Entre las primeras se consultaron cédulas reales y oficios del Consejo de Indias hallados en el Archivo General de Indias en Sevilla, como así también numerosas escrituras públicas recolectadas en el Archivo y Biblioteca Nacional de Bolivia, en la ciudad de Sucre. Los manuscritos editados corresponden a las sendas colecciones editadas por el prolífico historiador argentino Roberto Levillier a comienzos del siglo XX, como así también a tratados de la época escritos por 
prácticos en derecho o por magistrados que cumplieron funciones en el dilatado Orbe Indiano.

La centralidad que tuvo la Audiencia de Charcas durante los años de dominación castellana del Nuevo Mundo intenta, en este escrito, visualizarse a partir del estudio de su primer fiscal, el licenciado Jerónimo de Rabanal. Comprender la actuación de los magistrados locales, insertos en una matriz de pensamiento y accionar específica a la hora de realizar sus prácticas profesionales y personales, nos aproxima a desvelar el obrar de la justicia indiana centrando el análisis más en los hombres que la produjeron que en las acciones institucionales que la legislación nos legó.

\section{El Derecho como práctica social}

En un artículo de reciente aparición, Carlos Garriga nos invita a reflexionar sobre los procesos de cambios historiográficos que han acontecido en el quehacer del historiador (de la historia del derecho en particular, pero en la producción histórica en general) desplazando "la sociedad por la cultura como concepto clave para la organización del conocimiento histórico" (Garriga, 2020: 5). Centrado en el debate, que desde hace más de cuarenta años tiene inmersa a divergentes escuelas de la historia del derecho en torno al objeto de su disciplina, Garriga abre las páginas del trabajo anteriormente citado con las reflexiones del recordado iushistoriador español Francisco Tomás y Valiente en relación a pensar el "Derecho", no solo desde un aspecto formal y técnico (base de la producción histórico-jurídica de una gran parte del universo de historiadores del derecho), sino también desde otras conexiones fundamentales (sociales, políticas, culturales, antropológicas, etc.) que le den sentido y anclaje histórico, metodología por la cual Tomás y Valiente proponía, en la década del ' 80 del siglo XX, que debía discurrir la renovación de la producción jurídica.

Al leer las páginas de Garriga, recordé de inmediato el prólogo que Tomás y Valiente escribió como último trabajo antes de su infame asesinato el 14 de febrero de 1996, a la traducción al castellano del libro de Paolo Grossi El orden jurídico medieval (1996). Allí, al sintetizar y repensar sobre la obra del maestro italiano, Tomás y Valiente problematizaba: "El ordo iuris propuesto por teólogos y juristas no es pleno Derecho si no hay quién lo imponga. Desprovisto de su dimensión conflictual, el ordo iuris se nos presenta como una maravillosa construcción teórica, más propia de ángeles que de hombres" (Tomás y Valiente, 2003: 25). Esta reflexión del catedrático español ha guiado gran parte de mis trabajos de investigación sobre los diversos magistrados que cumplieron funciones en las Audiencias indianas. Ligado a ella, también está la sugerencia que realizó Víctor Tau Anzoátegui, y se publicara un año después de la desaparición física de Tomás y Valiente, en un libro que se convirtió en bitácora para quienes intentamos adentrarnos en la reconstrucción de las trayectorias de vida de los juristas indianos. Allí Víctor Tau proponía que

"el Derecho Indiano que cultivamos ha dejado frecuentemente en la sombra a los hombres y linajes familiares, a sus intereses, pasiones y apetencias. La arquitectura institucional, tan pacientemente recreada, necesita ser complementada con el conocimiento de quienes 
han operado en la creación y aplicación del derecho. Los mecanismos, a veces fríamente descriptos, no funcionan sino a través de la acción humana" (Tau Anzoátegui, 1997:57).

El necesario estudio de aquellos ministros que aplicaron el derecho a lo largo y ancho del dilatado Orbe Indiano, no puede estar descontextualizado de la cultura jurídica que cinceló durante siglos el arquetipo de lo que debía ser un iudex perfectus (juez perfecto). Escindir aquella cultura jurídica que le daba sentido a las acciones que realizaron los jueces del Antiguo Régimen, daría como resultado un trabajo carente de sentido explicativo de las razones contextuales que llevaron a los ministros indianos (o castellanos, da igual) a realizar ciertas prácticas. Una enorme avalancha de trabajos de historia social, que a partir de la década de 1990 centró sus ojos en los archivos judiciales y en las trayectorias de vida de los magistrados del Nuevo Mundo, se fascinó en describir prácticas corruptas, clientelares, de patronazgo, etc. dejando de lado la "cultura" jurídica y los utillajes mentales por los cuales discurría el accionar de dichos togados, cayendo en la trampa inversa de lo que criticaban a la historia dogmática del derecho. Mientras que estos últimos habían olvidado el accionar de los hombres en la aplicación del derecho, aquellos (los historiadores sociales) omitían la teoría y la jurisprudencia que dotaba de sentido las prácticas de los agentes judiciales que estaban historizando.

Pensar al Derecho como una "práctica social culturalmente mediada" (Garriga, 2020: 14) nos posiciona también en intentar comprenderla como praxis localizada. En los últimos años, la “discusión historiográfica mira con nuevos ojos los grandes horizontes imperiales y la riqueza y densidad propia del variado mundo de espacios locales que bullía por debajo de ellos", siendo así "un orden universal y muchos órdenes particulares sobre un mismo ámbito espacial [...] rasgo definitorio de la cultura jurídica que, configurada en los siglos bajomedievales, se proyectó sobre todo el período moderno" (Agüero, 2013: 92 y 93).

\section{Eloficiofiscal en unaculturajurídica tradicional}

La creación institucional, y la provisión de oficios, estuvo enmarcada dentro de aquella construcción jurídico-política que se desarrolló durante los siglos de la Época Moderna. Aquel mundo ordenado y tradicional (Hespanha, 1998: 58-70) estaba sustentado sobre la base de una,

“concepción jurisdiccional, composición pluralista y configuración jurisprudencial, para expresar respectivamente (i) la concepción del derecho como un orden declarativo a partir de principios religiosamente indisponibles, (ii) casuísticamente concretados por la tradición forjada en cada espacio de convivencia políticamente organizada en distintos-pero igualmente válidos- conjuntos normativos, (iii) que solo los iurisprudentes tenían -en su doble condición de tratadistas y de jueces o magistrados- el saber preciso para conciliar en cada caso hasta hallar la solución justa, o sea, ajustada a derecho" (Garriga, 2008: 49).

Se instituyó por tanto un modelo judicial de gobierno, en donde la jurisdicción centrada en el príncipe, se basaba ante todo en mantener en justicia y paz a su reino. Las complejidades emanadas de tales tareas, requirió con el tiempo, 
la delegación de parte de la jurisdicción real en distintos oficiales que le auxiliaban en los diversos ramos del gobierno temporal. Fue así que "el oficio, entonces, aparecía como un medio para que, a través de él, obrara la voluntad del príncipe [...] el servicio del oficio se volvía simplemente en un "hacer" o "actuar" una voluntad ajena: la del rey” (Barrientos Grandón, 2018: 90).

El oficio de fiscal tuvo una construcción histórica en Castilla que hunde sus raíces en los propios devenires de cómo se estructuró aquel orden jurídico-político a través de los siglos bajomedievales. Pese a ser un oficio que ganará importancia, a partir sobre todo de la reforma judicial llevada adelante por los Reyes Católicos en 1489, no son muchos los estudios centrados en sus funciones y deberes, si se los compara con los trabajos destinados a reflexionar sobre los oidores (López Nevot, 2013: 256). Tampoco se realizó una profusa investigación sobre los fiscales indianos, siendo tal vez los más centrales el de Fernando Arvizu (1986) en su comparación entre fiscales americanos y peninsulares, el libro de Santiago Suarez (1995) sobre el origen de los fiscales indianos, los trabajos de Abelardo Levaggi sobre los fiscales de la Audiencia de Buenos Aires en el siglo XVIII (1985, 1988, 1989a, 1989b, 1991 y 1994), la pormenorizada reconstrucción de Carolina Jurado sobre el fiscal Francisco Alfaro (2013 y 2014) y los estudios de Sergio Angeli (2010 y 2014) sobre el primer fiscal de la Audiencia de Lima en el siglo XVI.

Las áreas de actuación del procurador fiscal fueron construyéndose a partir de la teorización jurídica-canónica que terminó por cristalizarse bajo el reinado de Isabel y Fernando, quienes instituyeron al fiscal como una "institución directamente vinculada a los intereses de la monarquía en un triple aspecto: patrimonial, de justicia y de defensa de la realeza" (Alonso, 1982: 148). Estas amplias facultades, dotaron al oficio regio, en un lugar clave dentro de las Audiencias y Chancillerías "desarrollando sus funciones en pleitos penales, civiles y de hidalguía” (Garriga, 1994: 300).

En su traspaso a las Indias, las obligaciones del fiscal continuaron las descritas en las reglamentaciones castellanas y las insertas en las Ordenanzas de las Audiencias y Chancillerías de Valladolid y Granada, amén de las dictadas en las Ordenanzas antiguas de 1528 y en las posteriores Ordenanzas Generales para las Audiencias americanas de 1563. En su Tractatus de officio fiscalis (1606), la obra más detallada sobre el oficio fiscal escrita además por un letrado en ejercicio de la procuración en la Audiencia de Charcas, el licenciado Francisco de Alfaro describía los muchos deberes y obligaciones de la función. Ante la abrumadora tarea que les competía, el jurista Solórzano y Pereira, quién fuera oidor de la Audiencia de Lima y luego consejero de Indias, advertía a los oficiales fiscales que "guarden en todo la moderación debida, que es la que merece ser alabada. Y no permitan, que por negligencia vituperable pierdan, lo que fuere, o pudiere ser suyo, y se hallen necesitados de echar mano con codicia torpe a lo ageno" (Solorzano, 1739: 306).

La provisión del oficio fiscal, estructurada pacientemente en base a los saberes de una tradición textual que se hilvanaba en las tramas del ius commune, forjó un magistrado que supo ser, en 
palabras del también recordado jurista y oidor de la Audiencia Chile don Gaspar de Escalona y Agüero,

"la voz del Rey en sus causas, zelador de los que administran su Hacienda, sobrestante de los que la ordenan y reducen a calculo, inquiridor de los que la detentan, delator de los que la defraudan, Procurador de lo que conduce a su beneficio, y finalmente Protectory abogado del soberano Señor, con ardimiento licito y sin animo calumnioso" (Gaspar de Escalona y Agüero, 1775: 285-286).

\section{El fiscal Jerónimo Rabanal en Charcas}

Asentada la corte en Valladolid, se elevó consulta del Consejo de Indias el día 2 de julio de 1557, en donde se proponen los nombres de los oficios de oidores, fiscal y alguacil mayor para la creación de una Audiencia en la ciudad de La Plata de los Charcas. En ella aparece por vez primera la candidatura del licenciado Jerónimo de Rabanal al oficio de procurador fiscal. En el margen izquierdo el rey Felipe II anotó “'A ninguno destos letrados ni a los que se nombran para el oficio de alguaçil mayor conozco sinoal doctor Armendariz" (Archivo General de Indias-AGI, INDIFERENTE, 738, N.7). Un añoy tres meses después de la citada consulta, el 15 de agosto de 1558, se firmó la Real Provisión que nombraba al licenciado Rabanal como primer fiscal de la recientemente creada Audiencia de La Plata de los Charcas para

"que asi como nuestro promotor fiscal de nuestra justizia podáis pedir e demandar, acusar y defender todas aquellas cosas y cada una de las que cumplan a nuestro servicio, a la guarda del patrimonio realy a la execusion de nuestra justizia de la dicha nuestra Audiencia y acrecentamiento de nuestra rentas reales", adjudicándole un salario anual de cuatro mil pesos oro (AGI, LIMA, 567, L.8, f.417r-418r).

El flamantefiscaldeCharcas, era oriundo de Carrión de los Condes, una ciudad de larga trayectoria en el camino de Santiago y sede de cortes y concilios provinciales desde el siglo X. La pequeña villa alto medieval fue logrando privilegios y fueros, y se convirtió en un sitio de importancia durante la Reconquista castellana. Supo tener también la urbe de Carrión uno de los más importantes barrios judíos de toda la Península en el sigloXIII. Hacia el sigloXVI contaba con cerca de seis mil habitantes, varios hospitales y monasterios, además de una feria franca y el privilegio de que los soldados no usaran la villa como lugar de descanso sin previa autorización real. También fueron oriundos de Carrión de los Condes don Luis de Velasco y Ruíz de Alarcón, segundo virrey de Nueva España (1550-1564) y su hijo Luis de Velasco y Castilla, quien ocupó el oficio del virreinato mexicano en dos oportunidades (1590-1595 y 1607-1611) y fue también virrey del Perú (1596-1604), en donde fundó varias ciudades siendo una de ellas el importante centro minero de San Felipe de Austria de Oruro en Charcas (1604).

Los padres del fiscal Rabanal fueron doña Catalina de Lintorne y el bachiller Pedro de Rabanal, destacado abogado en Carrión de los Condes (AGI, Charcas 43). Su cuñado, el licenciado Bartolomé de Herrera, fue abogado de la Audiencia de Valladolid y una de las personas más influyentes de la ciudad vallisoletana. Graduado en Leyes, es muy 
probable que el licenciado Rabanal estudiase en Valladolid mientras la Corte estaba asentada en aquella ciudad, y que las conexiones familiares fueran importantes en su nombramiento como procurador fiscal de Charcas, dato que aún no he podido corroborar.

El licenciado Rabanal realizó su viaje a Indias entre los años 1559 y 1560. Para el año 1561 ya se encuentra cumpliendo funciones en la ciudad decana de los Andes del sur y sede del tribunal. La ciudad de La Plata se convirtió en el hogar del fiscal Jerónimo Rabanal y su esposa doña Juana de Herrera. Allí criaron seis hijas "las tres ya grandes con hedad suficiente para se cassar, y las otras tres mas pequeñas", y tuvieron también "otros quatro hijos varones" (AGI, Charcas 43, f. 2). Los diecisiete años en los cuales permaneció en el oficio fiscal, le permitieron al licenciado Rabanal llevar adelante una variada gama de actividades por fuera de sus obligaciones estatuidas, las cuales quedaron protocolizadas en las distintas escribanías que había en la ciudad charqueña.

El establecimiento de la Audiencia de Charcas el 7 de septiembre de 1561 por parte del presidente del cuerpo togado, el licenciado Pedro Ramírez de Quiñones, junto a los oidores Antonio López de Haro y Juan de Matienzo, sentarían las bases de nuevas relaciones sociales y políticas al interior de la urbe platense. El tribunal se completaría con la llegada del oidor Martín Pérez de Recalde y del secretario Tristán Sánchez unos meses después. Estos ministros fueron el elenco estable de las redes relacionales al exterior de la sede audiencial. Durante quince años, las amistades y rivalidades entre los letrados torcerán o anudarán diversas alianzas por fuera del tribunal, haciendo muy difícil de establecer el aislamiento social de los magistrados que con tanto ahínco la corona deseaba cumplir.

El licenciado Rabanal, a lo largo de su dilatado oficio fiscal, también estuvo implicado en aquellas relaciones anudadas por la actuación profesional. La disputa central dentro del tribunal se erigió entre los oidores Matienzo y Haro en contra del licenciado Recalde, "a veces con apoyo del fiscal Rabanal y otras con el del presidente Ramírez de Quiñones" (Presta, 2008: 120).

A fin de poder realizar ante el rey, el Consejo de Indias o el virrey, la entrega de sus méritos y servicios, el fiscal Rabanal protocolizó el 20 de septiembre de 1561, en la escribanía de Lázaro del Águila, un poder en favor del licenciado Monzón, a la sazón fiscal en la Audiencia de Lima; y con Diego Encinas, Francisco de Gálvez y el bachiller Bartolomé de Herrera, abogado en la Audiencia y Chancillería de Valladolid y cuñado como ya mencionamos de Rabanal (Archivo y Biblioteca Nacional de Bolivia-ABNB, EP 6: 229v - 230r). A muy poco tiempo de estar en la sede de su tribunal, el togado desplegó una red de relaciones que tuvieron como centro la ciudad de La Plata y cabeceras en Lima y Valladolid. Una interesante forma de poder aprovechar sus contactos y generar nuevos espacios de poder e influencia (Cañeque 2001, Imizcoz Beunza y Artola Renedo 2016, Presta 2008).

Pero si estas redes estaban pensadas en posicionar su nombre en la capital virreinal o en la sede de la corte metropolitana, a dos años de haberse 
instalado en La Plata, el 10 de mayo de 1563, el procurador de causas Juan Pérez protocolizó una escritura notarial en la escribanía de Gaspar de Rojas, por la cual otorgaba poder a favor del licenciado Jerónimo de Rabanal, como fiscal de la Audiencia, y a los restantes procuradores, García de Esquivel, Francisco de Torres, y Hernando de la Peña para que "judicial o extrajudicialmente cobren de cualquier persona todo lo que se le adeudare" (ABNB, EP 7:243v-244r). Se anudaban así también las relaciones al interior del espacio local, motorizada en este caso a partir de la afinidad del oficio que cumplían todos ellos dentro de la Audiencia.

La vida cotidiana del licenciado Rabanal, por fuera de su oficio fiscal, se desarrolló con actividades propias de cualquier vecino. Lo encontramos así comprando desde varias varas de paños para vestir a su familia a Gabriel Paniagua de Loayza y a don Antonio Vallejo (ABNB, EP 6: 456v-457r), como también varios artículos para la decoración de su casa, entre los que se hallaban lienzos y paños de diverso origen (ABNB, EP 17: 482r - 483r) Supo otras veces adquirir esclavos para labores domésticas (ABNB, EP 20: 334v-335r) y realizó algunas transacciones económicas al menudeo como la venta de una mula a Juan Gutiérrez de Veas por 275 pesos ensayados y marcados (ABNB, EP 7: 88v-89r).

Inser to en la concepción corporativa y estamental del Antiguo Régimen, la exteriorización por medio de la vestimenta y la ostentación de las posesiones materiales reforzaban el status y la dignidad a la cual pertenecía el licenciado Rabanal como parte de la destacada corporación letrada local.
Durante la segunda mitad del siglo XVI, se asistió a lo que Lawrence Stone denominó "la inflación de los honores", un momento en el cual los estratos superiores de la ciudadanía reforzaron los signos externos de distinción social como forma de disciplinamiento y control de los sectores más bajos y postergados (Stone, 1985: 52). El modo de vestir permitía reconocer a simple vista en qué grupo social se encontraba cada persona y las funciones que cumplía dentro de cada estamento. Las élites de la Época Moderna llevaron adelante todo un complejo rito de habitus que los ubicaba en la cúspide del "proceso civilizatorio" tan finamente descrito por Norbet Elías (1993). La instalación de la Audiencia en la ciudad de La Plata en 1561 convirtió a la urbe (fundada en 1538 por Pedro de Anzurez, marqués de Camporredondo) en una nueva corte provincial. La recreación de los usos y costumbres, tanto políticas como sociales, de la corte real eran indispensables en el sostenimiento del orden instituido por la religión y sostenido por el poder político-jurídico que la resguardaba. Para la élite platense, contar con una corte provincial les aseguraba un lugar de refinada cultura y de posicionamiento social sobre el resto de los habitantes de la zona (Bridikina, 2007: 249-271). Las nuevas sedes audienciales fueron el lugar en donde los modelos culturales de la aristocracia europea se imitaban y se hacían visibles a todo el cuerpo social (Torres Arancivia, 2006: 63-107).

\section{La voz del fiscal incardinada en un espacio local e institucional}

Los oidores supieron tener una presencia muy fuerte a lo largo del dominio castellano en América, tanto colegiadamente como individualmente hablando. 
La voz y las acciones de los magistrados indianos quedaron plasmadas en una infinidad de cartas y memoriales que se enviaban al Consejo de Indias o al propio monarca desde el inicio mismo de la instalación de los tribunales letrados. Junto a los oidores, los fiscales tuvieron que ir construyendo un espacio simbólico e institucional que no siempre les fue fácil. Durante los primeros años de funcionamiento de las Chancillerías allende el Atlántico, no siempre se respetaban las "honras y preeminencias" que la monarquía les delegaba en sus nombramientos a los fiscales, ya que los oidores fueron muy recelosos a la hora de ampliar el poder simbólico que significaba representar la persona del rey en los espacios ultramarinos.

La información recibida por el Consejo de Indias o el monarca ayudaban también en la gestión de unas posesiones tan extensas y fragmentadas sobre el mapa terrestre (Gaudin, 2017). La recolección de las comunicaciones suministrada en las interminables misivas enviadas por toda clase de oficiales mostraba también cómo el variopinto y muy diverso grupo de servidores reales se encargaban de la premisa fundamental de la monarquía católica: mantener en paz y justicia los reinos del príncipe.

En las cartas que el licenciado Rabanal enviaba a la metrópoli, hay una enorme cantidad de reclamos que tenían que ver con cómo los oidores de la Audiencia de Charcas le retaceaban al fiscal la información necesaria para ocuparse de los asuntos propios de su oficio. Fue así, que ante un conflicto por diezmos mal percibidos por los clérigos de Charcas, el cuerpo de magistrados se abroqueló ante la decisión tomada en el Real
Acuerdo y el fiscal raudamente notificó al monarca que "no me an dado el proceso ni testimonio ni quieren se me de aunque lo e pedido" (Levillier, 1918: 100). En la misma misiva, el licenciado Rabanal expuso las prácticas de sus compañeros de tribunal que ante la insistencia de su parte para saber sobre las cédulas enviadas desde Madrid "no lo e sabido por que el rregente y oidores no me an querido admitir a los acuerdos ni fuera de ellos; me dan parte mas de lo que ellos quieren" (Levillier, 1918: 101).

La actitud de excluir al procurador Rabanal del Real Acuerdo, el momento de mayor importancia de la Audiencia ya que allí el cuerpo colegiado de oidores se convertía clónicamente en monarquía (Clavero, 2006), no sucedía solamente en Charcas. El primer fiscal de la Audiencia de Lima, el licenciado Juan Fernández, atravesó los mismos problemas que su colega Rabanal diez años antes y también lo informó al rey el 11 de marzo de 1553 (Levillier, 1922: 71). La actitud de excluir a los fiscales del Real Acuerdo parecía una práctica recurrente, pese a que muy tempranamente el emperador don Carlos había enviado una Real Cédula en 1530, recopilada posteriormente, en donde enfatizaba: "En el Acuerdo de las sentencias no estén presentes los Relatores, Escribanos, ni otra persona, que no tenga voto por sí mismo sino fuere el fiscal" (Recopilación Ley XXX, Libro II, Capitulo XV). Sin dilatar su respuesta, Felipe II emitió en Madrid, el 15 de agosto de 1564, otra Real Cédula que estipulaba "al presidente y oidores de la audiencia real de la provincia de Los Charcas: que en los acuerdos que en ella se hicieren dejen estar y hallarse presente al fiscal 
de vuestra majestad" (Recopilación Ley V, Libro II, Título XVIII).

Ante la rápida respuesta del monarca, aunque sin poder dar cuenta del derrotero que siguió la cédula expedida desde la Corte, sabemos gracias al cedulario de la Audiencia de La Plata y de mano del secretario Tristán Sánchez, que:

“a veinte y nueve días del mes de julio de mil y quinientos y sesenta y seis años, los señores presidente y oidores de la real audiencia que reside en esta ciudad, habiendo visto la cedula real de su majestad, de suso contenida, la tomaron en sus manos y besaron y pusieron sobre su cabeza como carta y mandamiento de su rey y señor natural, y estando presente el licenciado Rabanal, fiscal de su majestad, dijeron que se guarde y cumpla como su majestad por ella lo manda, y que de hoy en adelante se halle el dicho fiscal en los acuerdos como su majestad lo manda, y el dicho señor presidente tomo y recibió juramento en forma de derecho del dicho licenciado Rabanal, fiscal de su majestad, sobre una señal de cruz, el cual lo hizo bien y cumplidamente, so cargo del cual se le encargo que tenga secreto de todo lo que en los dichos acuerdos se tratase y votare, el cual a la fuerza y conclusión del dicho juramente, dijo sí juro y amén, guardando lo que su majestad manda por la dicha cedula, y en fe de ello lo firmé: Tristán Sánchez. Que el fiscal entre en los acuerdos" (Enciso Contreras, 2005: 215).Casi cuatro años tardó el fiscal Rabanal en poder estar presente en la más importante reunión de la Audiencia. Esto fue posible por su insistencia pero también, como señala Margarita Gómez Gómez (2019), porque "los documentos eran la expresión escrita de la palabra del monarca y debían ser hon rados, obedecidos y respetados tanto en su contenido, como en su propia materialidad, como si se tratasen de la misma persona real".

Pero el derrotero del fiscal con sus compañeros de curul no terminaba allí. Lo dejaron estar presente por expresa orden del rey, pero no sería tan fácil para Rabanal que le respetaran las mismas "honras" que ellos tenían. Durante otros seis años más, lo hicieron estar de pie en las sesiones del Acuerdo, una clara demostración simbólica de que no estaba en igualdad de condición y status que los oidores. La insistencia ante el Consejo de Indias dio sus frutos finalmente el 15 de febrero de 1570, cuando por Real Cédula se estipuló “que el fiscal de la audiencia tenga asiento al lado del oidor menos antiguo" (Enciso Contreras, 2005: 284). Una vez más, el secretario Tristán Sánchez anotó al dorso de la cédula:

"en la ciudad de La Plata, a catorce días del mes de febrero de mil y quinientos y setenta y dos años, ante los señores presidente y oidores de la real audiencia que reside en esta ciudad, estando en acuerdo de justicia, ante mí Tristán Sánchez, escribano de cámara de la dicha real audiencia, el licenciado Rabanal, fiscal de su majestad, presentó la cédula de su majestad de esta otra parte contenida, y los dichos señores la obedecieron con el acatamiento debido, y dijeron que se haga y cumpla como su majestad lo manda, y que desde mañana el dicho fiscal se siente en la parte y lugar que la cedula real declara" (Enciso Contreras, 2005: 285). 
La constante escritura del licenciado Rabanal ante el rey o el Consejo de Indias ponía de manifiesto las exclusiones que llevaban adelante los magistrados charqueños sobre su oficio fiscal. No fueron simples caprichos o anécdotas efímeras las que se relataban, por el contrario, estaban insertas en una simbología ritual que patentizaba "la propia encarnación de la producción y negociación de las relaciones de poder" (Cañeque, 2004: 611). Las liturgias del poder, como tan bien fueron retratadas por Valenzuela Márquez (2001), cumplían una fuerza eficaz en la arena pública, pero en este caso en particular, también las vemos aparecer en el más íntimo y secreto espacio que tuvo la monarquía en ultramar. Un ejemplo claro de cómo las sociedades de antiguo régimen estructuraban sus sistemas de jerarquías y preeminencias socio-políticas tanto al interior como al exterior de las instituciones indianas.

Podemos inferir que los magistrados no estarían muy conformes con el fiscal Rabanal, ya que a lo largo de sus misivas, informaba de las constantes relaciones sociales que los letrados estaban conformando con los poderosos vecinos y encomenderos de la ciudad de La Plata. Sin ahorrar detalles, y exponiendo nombres y actitudes tomadas por el presidente y oidores, el 18 de junio de 1566, el licenciado Rabanal relató al Consejo de Indias que "dos mestizos el uno hijo de centeno y el otro de pedro de Hinojosa mataron en esta cibdad un ombre y presentaronse y estando presos trataron de que ellos se alcarian y que matarían a nuflo de chabes y que cuando mas no pudiesen se irían al ynga" (Levillier, 1918: 180). Los nombres de Diego Centeno y de Pedro de Hinojosa eran de los más respetados y recordados en Charcas. Fueron parte de los primeros pobladores de la región y habían recibido encomiendas tanto de manos de Francisco Pizarro como posteriormente de don Pedro de La Gasca por su lealtad a la corona ante el levantamiento de Gonzalo Pizarro acaecido en 1544 a raíz de las Leyes Nuevas. Diego Centeno poseyó en primera instancia la encomienda de Pocona de manos de Francisco Pizarro, y luego de la rebelión fue acrecentado con la de Puna, además de los asientos mineros que poseía en Potosí. Por su parte, Hinojosa tuvo inicialmente por Pizarro la riquísima encomienda de los Aullagas (con un ingreso anual de 22.500 marcos de oro y 900 tributarios) para luego ser recompensado, terminado el alzamiento, con la más rica aún encomienda de los Caracara-Charcas (Presta 2000, 257 y 258). Sin lugar a dudas el fiscal Rabanal estaba tocando hilos muy finos de las redes relacionales de los más encumbrados encomenderos charqueños.

Debido a la inacción por parte del presidente Ramírez de Quiñones y del resto de los oidores para efectivizar un castigo, Rabanal continuaba escribiendo al Consejo de Indias que él, como fiscal, "[pidió] se hiciese información y fuesen castigados", a lo cual el presidente Quiñones respondió "que era burla y que lo pidiese en audiencia publica" si así lo requería. Ante la insistencia del cuestor, una vez más, y hastiado seguramente, Ramírez de Quiñones miró fijamente al licenciado Rabanal y replicó "que su çapato acia mas diligencias que todos los fiscales del mundo y otros palabras" (Levillier, 1918: 180). Sin saber cómo finalizó esta disputa, en parte podemos darnos ahora una idea del por qué los letrados dejaron al licenciado Rabanal seis años de pie escuchando los reales Acuerdos. 
Dos años después de este incidente, el 28 de octubre de 1568, Rabanal escribió directamente al rey acusando a los oidores de haberle prestado diez mil pesos a Martín de Almendras (otro de los más encumbrados encomenderos locales) para que realizara una entrada en el Tucumán. Remarcaba el fiscal que los pesos prestados provenían de la Real Hacienda y que había cédula expresa de que ello no se realizara. Según él, los magistrados se “dan por desculpa que no es de hazienda rreal porque se los prestaron de los tributos que están depositados de los yndios que tubo en encomienda Hernando pizarro y con esto me ataxan la boca". Sin duda, los ministros del tribunal de Charcas querían taparle la boca al fiscal, y así lo hicieron cuando ante un nuevo préstamo realizado a Pedro de Castro por seis mil pesos, lo realizaron "[en] acuerdo sin mi y ansi no se de qué les prestaron los pesos dichos y las quentas tomanla presidente y oydores sin mi y no se me da dellas traslado aunque lo he pedido y ansy estoy ynposibilitado de saber de que se presento ni lo que gastan ni libran en haciendas rreales". Evidentemente el fiscal estaba haciendo lo que su oficio mandaba, y el Consejo de Indias lo sabía muy bien, ya que anotó en el margen de la carta "[enviar] cedula para que de aquí adelante no presten ninguna cosa de la caxa y lo que hubieren sacado della la buelvan con Relacion desto" (Levillier, 1918: 251). Pero en aquellas pujas de poder que fueron las Audiencias indianas, tal vez podamos entender mejor ahora la tirria que sentían los letrados ante el fiscal Rabanal.

Para rematar la información que estaba entregándole al Consejo en la misiva anteriormente citada, y porque también estaba en su derecho el licenciado Rabanal de estar fastidiado ante los atropellos de los oidores, ajustició con su pluma al tribunal apuntando que "en esta audiencia en las causas criminales se haze poca justicia y es por falta de voluntad de los juezes [...] a nadie hasta oy an castigado con rrigor conforme a derecho" (Levillier, 1918: 255).

\section{Consideraciones finales}

El 22 de octubre de 1567, a seis años de haber tomado posesión de su plaza de fiscal en la Audiencia de Charcas, en la escribanía de Lázaro del Águila, el licenciado Rabanal extendió un poder a favor de Juan Ramos para que su madre y su cuñado en Valladolid recibieran y cobraran 37 barras de plata que él les enviaba, y acogieran a dos de sus hijos, Jerónimo y Manuel de Rabanal, los cuales hacían el viaje junto al mencionado Ramos (ABNB, EP 11: 358r-359v y). La suma de las barras de plata equivalían a 4 cantos y 544.346 maravedís, menuda fortuna si recordamos que el salario del fiscal era de cuatro mil pesos oro al año. Aunque no podemos dar cuenta del origen de dichas barras de plata, podemos inferir que tanto las relaciones sociales anudadas por fuera del oficio fiscal, junto con actividades económicas desarrolladas a partir de uniones de intereses diversas, posicionaban a los magistrados indianos en lugares clave del entramado de poder local que les generaron ingentes ingresos anexos a su función oficial.

Casi un año después de haber enviado las barras de plata y a sus dos vástagos a la península, el 28 de octubre de 1568, el fiscal escribió al rey para pedirle que se llevara adelante una visita a la Audiencia, a fin de erradicar los males que se 
estaban produciendo por la falta de justicia, que la inacción de sus colegas letrados, realizaban como tantas veces él había informado (Levillier, 1918: 254). La visita al tribunal de Charcas se realizó finalmente en el año de 1570 por parte del licenciado Castro, quien había traspasado la gobernación del virreinato al recientemente llegado virrey don Francisco de Toledo en 1569. Concluida la averiguación y los testimonios recolectados en la sede audiencial, el licenciado Castro retornó a su oficio de consejero de Indias, y tres años más tarde, el 5 de mayo de 1573, se expidió la sentencia al licenciado Rabanal. Se le realizaron un total de 19 cargos, de los cuales la mitad le fueron exculpados. Los restantes, mayormente, estaban basados en no haber contradicho a los oidores en ciertas libranzas relacionadas con la Real Hacienda. Una vez analizados todos ellos, el Consejo determinó inculparlo con la categoría menor de "culpa", sin sancionarlo con pena pecuniaria ni inhibición de su cargo. Es por ello que siguió en su oficio de fiscal de la Audiencia junto al licenciado Matienzo, quien tampoco recibió suspensión de funciones.

El día 16 de julio de 1576, se informó al rey del deceso del primer fiscal que supo tener la Audiencia de Charca. De aquél elenco estable de letrados que recibió la ciudad de La Plata en 1561, solo permanecía en su curul un anciano pero aún enérgico oidor, el licenciado Matienzo.

La breve semblanza aquí realizada sobre el fiscal Rabanal, intentó ser una aproximación localizada a quienes sirvieron a la monarquía católica de los Austrias en sus dilatados dominios ultramarinos. Retomando la idea inicial con la cual abrí estas páginas, creo que desvelar las vidas y las prácticas de la inmensidad de oficiales reales con los que contó la dinastía Habsburgo, puede comprenderse mejor desde un análisis cultural de los contextos político-jurídicos en los cuales se fue forjando el imaginario de aquellos iudices perfectus, los cuales intentaron mantener en "paz y justicia" a una inmensa parte del mundo conocido por aquellos siglos.

\section{Referencias citadas}

\section{Fuentes de archivo}

Archivo General de Indias (AGI)

Indiferente, 738

Lima, 567

Charcas, 43

Archivo y Biblioteca Nacional de Bolivia (ABNB)

Escritura Pública, Nro. 6

Escritura Pública, Nro. 7

Escritura Pública, Nro. 11

Escritura Pública, Nro. 17

Escritura Pública, Nro. 20

Fuentes secundarias

Agüero, A. (2013): “Derecho local y localización del 
Derecho en la tradición jurídica Hispana. Reflexiones a partir del caso de Córdoba del Tucumán”, en Tau Anzoátegui, V. y A. Agüero (2013): El Derecho local en la periferia de la Monarquía Hispana. Río de la Plata, Tucumán y Cuyo. Siglos XVI-XVIII, Buenos Aires, Instituto de Investigaciones de Historia del Derecho.

Alfaro, F. (1606): Tractatus de Officio Fiscalis, Deque Fiscalibus Privilegiis, Valladolid, Apud Ludouicum Sanchez.

Alonso Romero, M. P. (1982): El proceso penal en Castilla (siglo XIII al XVIII), Salamanca, Universidad de Salamanca

Angeli, S. (2010): “Notas sobre el Lic. Juan Fernández, fiscal de la Real Audiencia de Lima en el período 1552-1569", en AA. VV., Perspectivas y desafíos de la Historia del Derecho Argentino, Córdoba, Advocatus.

Angeli, S. (2014): “Un temprano juicio de residencia colonial: el licenciado Juan Fernández, primer fiscal de la Audiencia de Lima”, Revista Investigaciones y Ensayos, 60, pp. 437-458.

Arvizu, F. (1986): "El fiscal de la Audiencia en Indias y su paralelo castellano (siglos XVI y XVII), en Poder y presión fiscal en la América española (siglos XVI, XVII y XVIII), Valladolid, VI Congreso del Instituto Internacional de Historia del Derecho Indiano, pp. 203-233.

Barrientos Grandón, J. (2018): “El oficio y su proyección en el lenguaje de las residencia. Bueno, recto e limpio juez", en Andujar Castillo, F. y P. Ponce Leiva, (2018), Debates sobre la corrupción en el Mundo Ibérico, siglos XVI-XVII, Alicante, Biblioteca Virtual Miguel de Cervantes.
Bridikina, E. (2007): Theatrum Mundi. Entramados del poder en Charcas colonial, La Paz, IFEA-Plural Editores.

Cañeque, A. (2001): "Cultura vicerregia y Estado colonial. Una aproximación crítica al estudio de la historia política de la Nueva España”, Historia Mexicana, LI (1), pp. 5-57.

Cañeque, A. (2004): “De sillas y almohadones o de la naturaleza ritual del poder en la Nueva España de los siglos XVI y XVII", Revista de Indias, LXIV(232), pp. 609-634.

Clavero, B. (2006): “Justicia y Gobierno, Economía y Gracia”, Moya Morales, J., E. Quesada Dorador y D. Torres Ibáñez, Real Chancillería de Granada: V Centenario (1505-2005), Granada, Junta de Andalucía.

Elías, N. (1993): El proceso de la civilización. Investigaciones sociogenéticas y psicogenéticas, México, Fondo de Cultura Económica.

Enciso Contreras, J. (2005): Cedulario de la Audiencia de La Plata de Los Charcas, siglo XVI, Sucre, Archivo y Biblioteca Nacionales de Bolivia.

Escalona y Agüero, G. (1755) [1647]: Gazophilacium Regium Perubicum, Madrid, Ex Typpographia Blasii Roman.

Garriga, C. (1994): La Audiencia y las Chancillerías castellanas (1371-1525): historia política, régimen jurídico y práctica institucional, Madrid, Centro de Estudios Constitucionales.

Garriga, C. (2020): “De qué hablamos los historiadores del Derecho cuando hablamos de Derecho?", Revista 
Dereito Mackeinze, 14 (1), pp. 1-24.

Garriga, C. (2009): “Gobierno y Justicia: El gobierno de la justicia”, Lorente, Marta (Coord.), Lajurisdicción contencioso-administrativa en España. Una historia de sus orígenes, Madrid, Consejo General del Poder Judicial, pp. 45-113.

Gaudin, G. (2017): “Vencer la distancia: Actores y prácticas del gobierno de los imperios español y portugués”, Nuevo Mundo Mundos Nuevos, Disponible en web: http://journals.openedition.org/nuevomundo/71453 [Consulta: 15 de mayo del 2020].

Gerardo Suárez, S. (1995): Los fiscales indiano: origen y evolución del Ministerio público, Caracas, Academia Nacional de la Historia.

Gómez Gómez, M. (2019): “Escribir la norma: problemas de recepción, acatamiento y publicación de los documentos reales en las Indias durante el Antiguo Régimen", Les Cahiers de Framespa, Disponible en web: https://journals.openedition.org/framespa/5617 [Consulta: 20 de mayo del 2020].

Grossi, P. (1996): El orden jurídico medieval, Madrid, Marcial Pons.

Hespanha, A. M. (1998): Cultura jurídica europea. Sintesis de un milenio, Madrid, Tecnos.

Imícoz Beunza, J. M. y A. Artola Renedo (2016): Patronazgo y clientelismo en la Monarquía Hispanica (siglos XVI-XIX), Bilbao, Servicio Editorial Universidad del País Vasco.

Jurado, C. (2013): “Memorial cerca de las congruençias de la perpetuydad de las encomiendas de los indios: un escrito inédito del licenciado don Francisco de Alfaro, Charcas, circa 1599. Estudio crítico y transcripción", Revista de Historia del Derecho, Buenos Aires, 46, pp. 45-71.

Jurado, C. (2014), “Un fiscal al servicio de Su Majestad: don Francisco de Alfaro en la Audiencia de Charcas, 1598-1608”, Revista Población y Sociedad, 21, pp. 99-132.

Levaggi, A. (1985): "El concepto de derecho según los fiscales de la segunda Audiencia de Buenos Aires (1784-1810)", Revista Chilena de Historia del Derecho, 11 , pp. 245-259.

Levaggi, A. (1988): El virreinato rioplatense en las visitas fiscales de José Márquez de la Plata, Buenos Aires, Universidad del Museo Social Argentino.

Levaggi, A. (1989a): "Método e ideología de un fiscal de la Audiencia de Buenos Aires: José Márquez de la Plata", Anuario Mexicano de Historia del Derecho, 1, pp. 95-112.

Levaggi, A. (1989b): Los escritos del fiscal de la Audiencia de Buenos Aires, Manuel Genaro de Villota, Buenos Aires, Fundación para la Educación, la Ciencia y la Cultura.

Levaggi, A. (1990): “Aspectos del derecho penal indiano según José Márquez de la Plata y manuel Genaro de Villota”, en Estudios en honor de Alamiro de Ávila Martel, Santiago de Chile, Anales de la Universidad de Chile, pp. 297-333

Levaggi, A. (1994): “Aspectos del procedimiento judicial indiano según la doctrina de los fiscales José Márquez 
de la Plata y Manuel Genaro de Villota (1784-1810)", Historia, Instituciones, Documentos, 21, pp. 367-389

Levillier, R. (1918): La Audiencia de Charcas. Correspondencia de presidentes y oidores, Madrid, Juan Pueyo Editor

Levillier, R. (1922): Audiencia de Lima: correspondencia de presidentes y oidores, Madrid, Juan Pueyo Editor.

López Nevot, J. A. (2013): “Pedir y demandar, acusar y defender. Los procuradores fiscales de las Audiencias y Chancillerías castellanas", Anuario de Historia del Derecho Español, LXXXIII, pp 255-324.

Presta, A. M. (2000): Encomienda, familia y negocios en Charcas Colonial. Los encomenderos de La Plata, 15501600, Lima, Instituto de Estudios Peruanos.

Presta, A. M. (2008): "Entre la vara y los indios. La sociedad de Charcas frente a parejas imposibles, 1560-1580", Allpanchis Phuturinqa, 71, pp. 113-139.

Recopilación de Leyes de los Reinos de Indias, (1998) [1680], Madrid, Edición facsímil Centro de Estudios Políticos y Constitucionales-Boletín Oficial del Estado.

Solorzano Pereira, J. (1739) [1647]: Política Indiana, Madrid, Imprenta Gabriel Ramírez.

Stone, L. (1985): La crisis de la aristocracia (1558-1641), Madrid, Alianza Editorial.

Tau Anzoátegui, V (1997): Nuevos Horizontes en el estudio del Derecho indiano, Buenos Aires, Instituto de Investigaciones de Historia del Derecho.
Tomás y Valiente, F. (2003): Manual de Historia del Derecho Español, Madrid, Tecnos.

Torres Arancivia, E. (2006): Corte de virreyes. El entorno del poder en el Perú del siglo XVII, Lima, Fondo Editorial Pontificia Universidad Católica del Perú.

Valenzuela Márquez, J. (2001): Las liturgias del poder: celebraciones públicas y estrategias persuasivas en Chile colonial (1609-1709), Santiago de Chile, Lom Ediciones. 